\title{
Short Term Outcome of Ilioinguinal Neurectomy in Reducing Chronic Pain after an Inguinal Hernia
}

\author{
K. Saravanan ${ }^{1}$, T. Umamaheswari² \\ ${ }^{1}$ Associate Professor, Department of Surgery, Government Theni Medical College, Tamilnadu, ${ }^{2}$ Assistant Professor, \\ Department of Surgery, Government Theni Medical College, Tamilnadu, India
}

Corresponding author: Dr. T. Umamaheswari, Assistant Professor, Department of Surgery, Government Theni Medical College, Tamilnadu, India

DOI: http://dx.doi.org/10.21276/ijcmsr.2019.4.1.19

How to cite this article: K. Saravanan, T. Umamaheswari. Short term outcome of ilioinguinal neurectomy in reducing chronic pain after an inguinal hernia. International Journal of Contemporary Medicine Surgery and Radiology. 2019;4(1):A78-A80.

\section{A B S T R A C T}

Introduction: Chronic neuralgia is the most serious and debilitating long-term complication after mesh repair of a groin hernia. The ilioinguinal nerve is the most commonly involved. Current research aimed to study the short term outcome of ilioinguinal neurectomy in reducing chronic pain after an inguinal hernia

Material and methods: 80 patients underwent unilateral inguinal hernia via Lichtenstein's method were divided into 2 groups, neurectomy group and nerve preserved group. VAS were collected at day 1, day 3, day 7, 1 month, 6 months.

Results: Mean VAS a month after surgery in the nerve-preserved group and in the nerve-excised group were $0.22 \pm 0.2$ and $0.9 \pm 0.2$, respectively. Mean VAS, six months after surgery in the nerve-preserved group and in the nerve-excised group were $0.1 \pm 0.2$ and $0.28 \pm 0.4$, respectively.

Conclusion: This study recommends that Ilioinguinal neurectomy may be considered as a routine surgical step during open mesh hernia repair.

Keywords: An Inguinal Hernia, Ilioinguinal Nerve, Neurectomy

\section{INTRODUCTION}

Inguinal hernia surgery is one of the most common surgeries performed, and persistent postoperative pain is uncommon. ${ }^{1,2}$ Chronic pain is defined generally as pain lasting $>3$ months, but the studies on postoperative chronic pain often address the presence of pain several years after inguinal herniorrhaphy. ${ }^{3}$ The prevalence of groin pain after inguinal hernia repair has been reported to be $20-30 \% .{ }^{4}$ When these pain syndromes occur, which can happen irrespective of the repair type performed, they cause enough disability for patients to seek therapies options ranging from nonsteroidal anti-inflammatory drugs to physical therapy and even to additional surgery (for neurectomy, neuroma excision, etc.).5, Routine excision of the ilioinguinal nerve in an attempt to decrease the incidence of chronic inguinodynia has been proposed,5,6 yet controversies persist, and the procedure is not widely accepted. Because nerve excision eliminates postsurgical pain caused by entrapment, inflammation, or fibrotic reactions around the nerve, there seem to be some theoretic benefit of this practice. ${ }^{7,8}$

Current research aimed to study the short term outcome of ilioinguinal neurectomy in reducing chronic pain after an inguinal hernia

\section{MATERIAL AND METHODS}

This randomized controlled trial was conducted department of General Surgery, Government Theni Medical College and Hospital. Patients were selected randomly as per inclusion and exclusion criteria and divided into 2 groups. Patient informed consent was obtained before surgery.

Inclusion criteria: Male patients admitted for unilateral inguinal hernia via Lichtenstein's method were included.

Exclusion criteria: a recurrent hernia, history surgery in abdomen, diabetes and other neurological problems.

Neurectomy group patients underwent inguinal hernia mesh repair and neurectomy via Lichtenstein's method. Nerve preserved group patients were underwent inguinal hernia mesh repair via Lichtenstein's method with nerve preservation. Patients were followed for 6 months at day 1 , day 3, day 7, 1 month and 6 months. Post-surgical analgesic medications were provided.

Patients demographic details, preoperative pain, postoperative pain, complications during surgery were collected. Visual analog scales were used to measure the pain score. Patients were advised to return to their routine work after discharge to evaluate the pain scale.

\section{RESULTS}

In this study, 40 patients were included in each group were studied at a different interval. Most of the patients were in between 31 to 40 years of age in both groups, followed by 41 to 50 years (figure-1). In our study $58 \%$ of patients underwent right indirect hernia. The least was of left direct hernia. The 


\begin{tabular}{|c|l|c|c|}
\hline \multicolumn{2}{|l|}{ VAS } & Neurectomy & $\begin{array}{c}\text { Nerve } \\
\text { preserved }\end{array}$ \\
\hline \multirow{2}{*}{1 month } & Pain at rest & 1 & 6 \\
\cline { 2 - 4 } & Pain during activities & 2 & 2 \\
\hline \multirow{2}{*}{6 month } & Pain at rest & 0 & 3 \\
\cline { 2 - 4 } & Pain during activities & 1 & 2 \\
\hline
\end{tabular}

Table-1: Comparison of Pain during rest and during activities

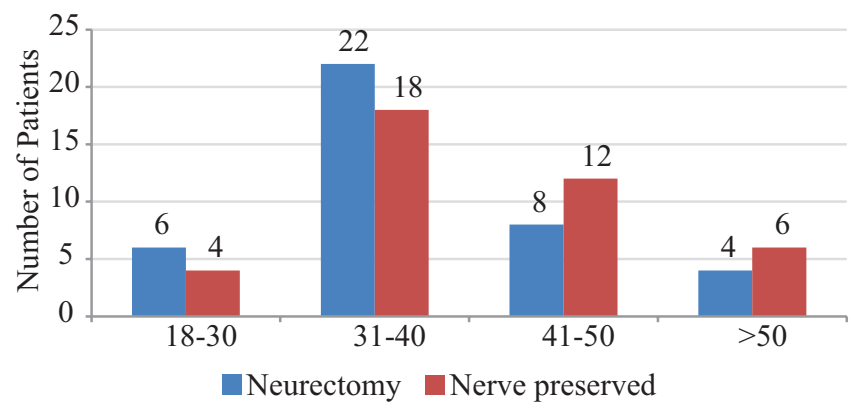

Figure-1: Distribution of Age group

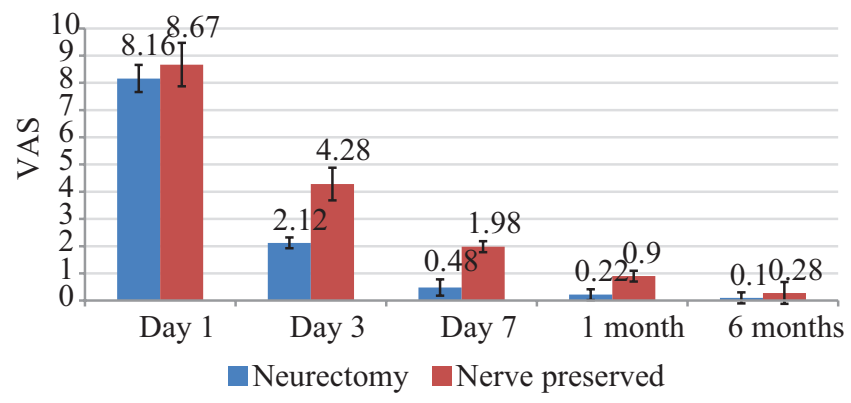

Figure-2: Distribution of VAS between groups

pain was noted in $16 \%$ of patients during the presentation. In $38 \%$ cases, hernia extended up to inguinal canal, $38 \%$ cases a hernia extended up to the root of the scrotum and in $12 \%$ cases a hernia extended up to bottom of the scrotum. Visible peristalsis was observed in $8 \%$ participants. $24 \%$ cases had tenderness on palpation. VAS difference was observed from day 1 , day 7 the pain was $0.48 \pm 0.3$ in Neurectomy group and $1.98 \pm 0.2$ in nerve preserved group, respectively. Mean VAS a month after surgery in the nerve-preserved group and in the nerve-excised group were $0.22 \pm 0.2$ and $0.9 \pm 0.2$, respectively. Mean VAS, six months after surgery in the nerve-preserved group and in the nerve-excised group were $0.1 \pm 0.2$ and $0.28 \pm 0.4$, respectively (figure- 2 , table- 1 ). The incidence of hypoesthesia in the neurectomy group was $4 \%$, nerve preserved group patients had 2\% hyperesthesia at 6 months follow-up.

\section{DISCUSSION}

In recent years, the social evolution and professional interest in reaching higher levels of excellence have stimulated a change of attitude towards other indicators related to postoperative comfort and quality of life. Within this context, chronic pain following surgery has become the new center of attention for surgeons, embodied in the majority of studies and publications on inguinal hernias. Residual pain should be viewed as an essential endpoint when assessing the outcome of hernia surgery.
Ravichandran et al conducted a pilot study comparing preservation or division of the ilioinguinal nerve in an inguinal hernia open mesh repairs. Twenty patients with bilateral hernias were randomized to nerve preservation on one side and division on the other. At 6 months postoperatively, the pain was present in 1 of 20 patients (5\%) on the nerve-preserved side versus 0 of 20 patients $(0 \%)$ on the nerve division side. The numbness was present in 0 of $20(\%)$ on the nerve-preserved side versus 2 of 20 patients (10\%) on the nerve divided side. These differences were all nonsignificant and led the authors to conclude that elective division of the ilioinguinal nerve was not associated with a significant increase in postoperative symptoms in inguinal hernia repairs. ${ }^{8}$ Our study showed a difference in the VAS of the two groups at 1 month and 6-month postoperative evaluation. The decrease in the incidence of postoperative neuralgia in the nerve excision group was not accompanied by an increase in postoperative paresthesia

Picchio and colleagues who suggested that nerve preservation and nerve division have similar incidences of pain and that intraoperative nerve division just leads to an increased rate of wound anesthesia. ${ }^{9}$

Routine neurectomy has since progressed to the realm of inguinal hernia repairs, and routine ilioinguinal nerve division during inguinal hernia repairs has become increasing popular in surgical practice. Noticeable decreases in patient symptoms of postoperative pain seem to be the major driving influence.

\section{CONCLUSION}

Neurectomy is an appropriate solution for reducing postoperative chronic pain following Lichtenstein inguinal hernia repair. This study recommends that Ilioinguinal neurectomy may be considered as a routine surgical step during open mesh hernia repair.

\section{REFERENCES}

1. Aasvang E, Kehlet $\mathrm{H}$ : Chronic postoperative pain: the case of inguinal herniorrhaphy. Br J Anaesth 2005; 95(2):69-76.

2. Bay-Nielsen $M$, Nilsson E, Nordin $\mathrm{P}$, Kehlet $\mathrm{H}$ : Chronic pain after open mesh and sutured repair of indirect inguinal hernia in young males. Br J Surg 2004;91(2):1372-1376.

3. Classification of chronic pain. Descriptions of chronic pain syndromes and definitions of pain terms. Prepared by the International Association for the Study of Pain, Subcommittee on Taxonomy. Pain Suppl 1986;3(6):S1226.

4. Kehlet H, Bay-Nielsen M, Kingsnorth A. Chronic post herniorrhaphy pain-a call for uniform assessment. Hernia 2002;6(6):178-81.

5. Fitzgibbons RJ Jr, Filipi CJ, Quinn TH, et al. Inguinal hernia. In: (editor) Schwartz's Principles of Surgery. 8th ed. McGraw Hill 2005; 1385-3.

6. Geis WP, Singh K, Gillian GK. An algorithm for the treatment of chronic pain after inguinal herniorrhaphy. In: Fitzgibbons RJ Jr, Greenburg AG (editors) Nyhus and Condon's Hernia. 5th ed. Philadelphia, PA: Lippincott Williams and Wilkins; 2002: 307-16. 
7. Dittrick GW, Ridl K, et al. Routine ilioinguinal nerve excision in inguinal hernia repairs. Am J Surg 2004;188(1):736-40.

8. Ravichandran D, Kalambe BG, Pain JA. Pilot randomized controlled study of preservation or division of ilioinguinal nerve in open mesh repair of inguinal hernia. Br J Surg 2000;87(6):1166-7.

9. Picchio M, Marcello P, Palimento D. RCT of preservation or elective division of ilio inguinal nerve on open mesh repair. Arch Surg. 2004;139(8):755-8.

Source of Support: Nil; Conflict of Interest: None

Submitted: 01-02-2019; Accepted: 03-03-2019; Published online: 13-03-2019 